Article

\title{
Hydroxymethylation of Furfural to HMF with Aqueous Formaldehyde over Zeolite Beta Catalyst
}

\author{
Shun Nishimura * and Atsuki Shibata \\ Graduate School of Advanced Science and Technology, Japan Advanced Institute of Science and Technology, \\ 1-1 Asahidai, Nomi, Ishikawa 923-1292, Japan; s1610227@jaist.ac.jp \\ * Correspondence: s_nishim@jaist.ac.jp; Tel.: +81-761-51-1610
}

Received: 24 February 2019; Accepted: 28 March 2019; Published: 31 March 2019

\begin{abstract}
Hydroxymethylation of 2-furaldehyde (furfural) toward 5-hydroxymethyl-2-furaldehyde (HMF) was examined in this work among various zeolites with an aqueous formaldehyde as a reagent in a batch and a flow reactor system. It was found that the zeolite beta gave high activity and good reusability with calcination treatment before each run for the target reaction in the batch system. The unique stability of the HMF yield in the liquid-flow system was also observed only in the case of zeolite beta. The effect of the $\mathrm{SiO}_{2} / \mathrm{Al}_{2} \mathrm{O}_{3}$ ratio in the zeolite beta suggested that hydrophobicity would be an important factor in faster hydroxymethylation with an aqueous formaldehyde reagent. The highest turnover frequency (TOF) for HMF production was found to be $2.4 \mathrm{~h}^{-1}$ in the case of zeolite beta with $\mathrm{SiO}_{2} / \mathrm{Al}_{2} \mathrm{O}_{3}=440$ in the batch reactor system. An approximately $30 \%$ yield for $\mathrm{HMF}$ was achieved under optimum conditions for zeolite beta catalysts.
\end{abstract}

Keywords: 2-furaldehyde; 5-hydroxymethyl-2-furaldehyde; formaldehyde; hydroxymethylation; zeolite beta

\section{Introduction}

Catalytic biomass transformations towards highly value-added chemicals and materials have been an attractive research area in recent decades in relation to constructing a green and sustainable future society [1-6]. Furaldehydes are known as key platform compounds for biomass transformations in lignocellulosic biomass resources. In particular, 5-hydroxymethyl-2-furaldehyde (HMF) is the most important furaldehyde: it possesses two functionalities of formyl and hydroxyl groups on a furan ring at the second and fifth positions and this character enables various successive transformations to afford 2,5-furandicarboxylic acid [7,8], 2,5-diformylfuran [9,10], 2,5-bis(hydroxymethyl)furan (BHMF) [11,12], 2,5-dimethylfuran [13-15], 5-hydroxymethylfurfurylamine (HMFA) [16], 1,6-hexanediol [17], levulinic acid [18,19], aldol-adducts [20], and so on [21-23]. On the other hand, 2-furaldehyde (furfural), an abundant furaldehyde which is producible at the plant scale with a large quantity, has also permitted many conversions towards furoic acid [24,25], furfuryl alcohol [26,27], 2-methylfuran [28,29], furfuriyamine [30,31], 1,5-pentandiol [32,33], succinic acid [34], condensation products [35-37], cyclopentenones [38-40] and so on [41], as well as HMF reaction protocols. However, the number of possible derivatives of furfural and those impacts has been much less than those of HMF [1,6]. Apparently, the structural character of furfural, a formyl group linked on a furan ring at the second position, decreases its potential as a starting material in comparison with HMF.

To resolve this weakness of furfural, we have recently examined the direct hydroxymethylation of furfural and its derivatives (C5) with an aqueous formaldehyde reagent to produce the corresponding HMF-like derivatives (C6), a furan ring composed of two functional groups, by using a sulfuric functionalized resin catalyst in a batch and a liquid-flow reactor system [42]. The study carried out a survey of reactivity for the hydroxymethylation reaction among four types of Amberlyst 
resins constructed with a different acidity and/or surface nature. The Amberlyst-15 was found to be the best resin catalyst with a $43.1 \%$ yield and $57.5 \%$ selectivity for HMF production in a batch reaction system. It possessed significant reusability and applicability in the generation of furfural derivatives such as BHMF, HMFA, and 5-hydroxymethyl-2-furancarboxylic acid (HMFCA). However, there seems to be a great challenge in fabricating a resin-catalyzed system for the hydroxymethylation of furfural cost-effectively.

According to previous works, Moreau and co-workers have contributed important discussion on the direct hydroxymethylation of furaldehydes with $37 \%$ aqueous formaldehyde in the presence of dealuminated mordenite as a catalyst [43-46]. It is noteworthy that they revealed the importance of the hydrophobicity of highly dealuminated mordenite to the activity of hydroxymethylation of furfuryl alcohol towards BHMF by aqueous formaldehyde [46]. Because a lot of effort has been put into the synthesis of zeolite catalysts at the plant scale, it is likely that the development of zeolite-catalyzed hydroxymethylation of $\mathrm{C} 5$ to $\mathrm{C} 6$ furaldehydes has a fair chance of adding to sustainable technology in an economical manner.

In this work, we studied the hydroxymethylation of furfural to HMF in aqueous formaldehyde as a dual solvent and reagent (Scheme 1) with four different types of zeolite catalysts. The importance of the hydrophobic nature of the highly active zeolite beta catalyst composed of different $\mathrm{SiO}_{2} / \mathrm{Al}_{2} \mathrm{O}_{3}$ ratios was also investigated. This study is expected to be interesting and gives new insight into how to further the design of cheaper and/or more advanced systems for the upgrading of furaldehydes.

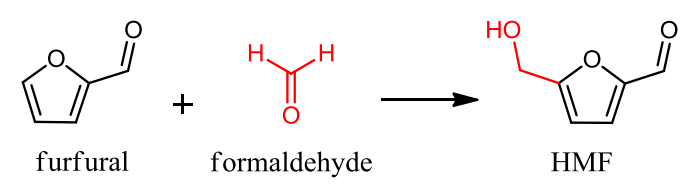

Scheme 1. Hydroxymethylation of furfural to 5-hydroxymethyl-2-furaldehyde (HMF) with a formaldehyde reagent.

\section{Results and Discussions}

\subsection{Catalyst Structure and Physicochemical Properties}

During our initial survey of the effects of zeolite reactivity on HMF production through the hydroxymethylation of furfural, four conventional types of zeolites were investigated. The Japan Reference Catalyst (JRC) Committee of the Catalysis Society of Japan (Tokyo, Japan) kindly supplied four types of zeolites, and these were calcined at $823 \mathrm{~K}$ for $5 \mathrm{~h}$ before use. The results of the X-ray diffraction (XRD) analysis of the JRC supplied zeolites are shown in Figure 1a. In comparison with the international centre for diffraction data (ICDD) database obtained through a PDXL software (Rigaku Corp., Tokyo, Japan; ver.1.8.0.3) search and fitting function, JRC-Z-HB150(1) $\left(\mathrm{SiO}_{2} / \mathrm{Al}_{2} \mathrm{O}_{3}\right.$ = 150), JRC-Z5-90H(1) $\left(\mathrm{SiO}_{2} / \mathrm{Al}_{2} \mathrm{O}_{3}=90\right)$, JRC-Z-HM20(5) $\left(\mathrm{SiO}_{2} / \mathrm{Al}_{2} \mathrm{O}_{3}=18.3\right)$, and JRC-Z-HY5.5 $\left(\mathrm{SiO}_{2} / \mathrm{Al}_{2} \mathrm{O}_{3}=5.6\right)$ fitted well in accordance with the typical patterns of zeolite beta (card no. 00-056-0467), ZSM-5 (card no. 00-045-0120), mordenite (card no. 00-043-0171), and zeolite Y (card no. 00-040-0336), respectively. JRC-SAH-1 $\left(\mathrm{SiO}_{2} / \mathrm{Al}_{2} \mathrm{O}_{3}=2.1\right)$ displayed a broad peak

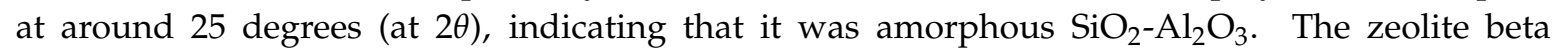
samples composed of different $\mathrm{SiO}_{2} / \mathrm{Al}_{2} \mathrm{O}_{3}$ ratios were supplied by the JRC and Tosoh Corporation (Tokyo, Japan): JRC-Z-HB25(1) $\left(\mathrm{SiO}_{2} / \mathrm{Al}_{2} \mathrm{O}_{3}=25\right), \mathrm{HSZ}-941 \mathrm{HOA}\left(\mathrm{SiO}_{2} / \mathrm{Al}_{2} \mathrm{O}_{3}=42.2\right), \mathrm{HSZ}-960 \mathrm{HOA}$ $\left(\mathrm{SiO}_{2} / \mathrm{Al}_{2} \mathrm{O}_{3}=104\right)$, HSZ-980HOA $\left(\mathrm{SiO}_{2} / \mathrm{Al}_{2} \mathrm{O}_{3}=440\right)$, and HSZ-990HOA $\left(\mathrm{SiO}_{2} / \mathrm{Al}_{2} \mathrm{O}_{3}=1700\right)$. These also possessed clear beta structural forms in all cases, as determined by XRD (Figure 1b). 

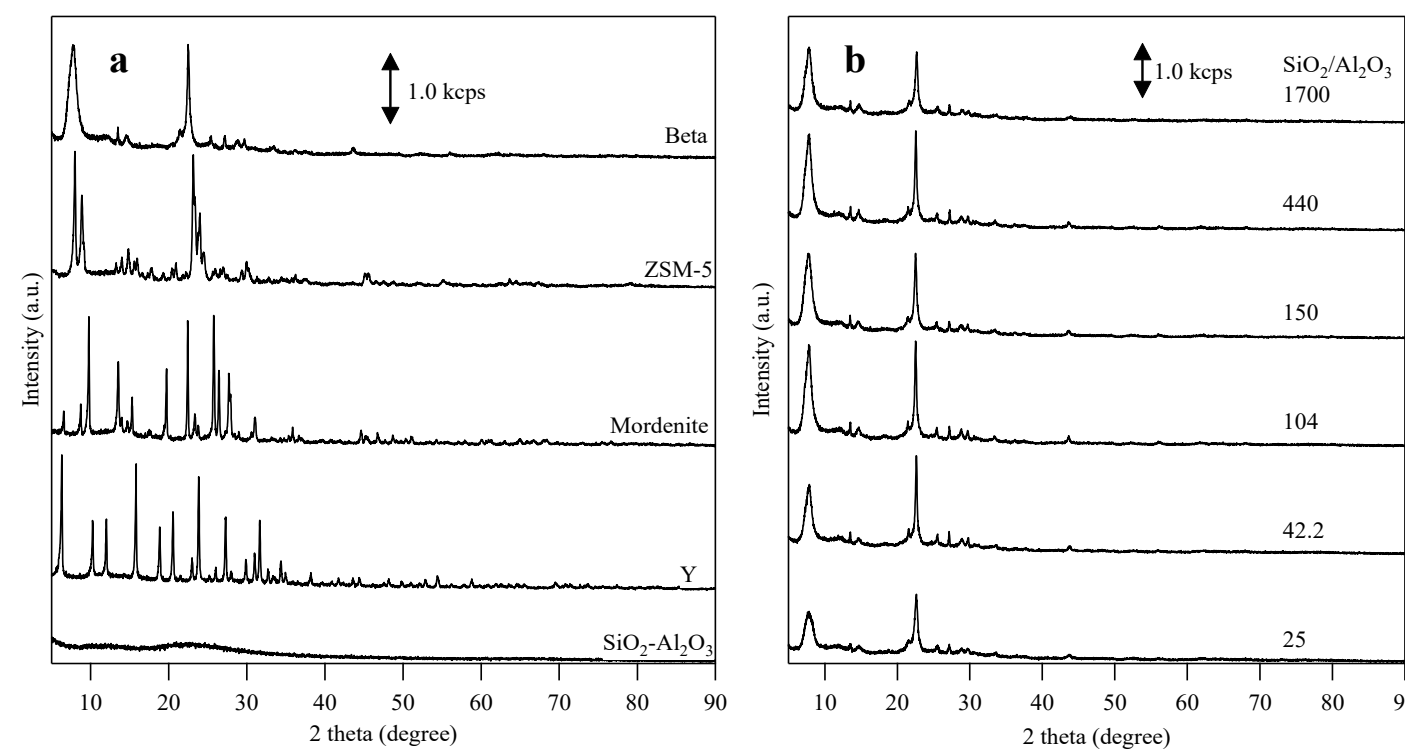

Figure 1. X-ray diffraction (XRD) patterns of (a) four types of reference zeolites and normal $\mathrm{SiO}_{2}-\mathrm{Al}_{2} \mathrm{O}_{3}$ and $(\mathbf{b})$ zeolite beta samples composed with various $\mathrm{SiO}_{2} / \mathrm{Al}_{2} \mathrm{O}_{3}$ ratios.

Pore size distribution and specific surface area were determined by $\operatorname{Ar}(>99.999$ purity) adsorption isotherms at $87 \mathrm{~K}$ using BELSORP-max (BEL JAPAN, INC., Osaka, Japan). The samples (100 mg) were pretreated at $623 \mathrm{~K}$ for $6 \mathrm{~h}$ under vacuum before measurement. A micropore size distribution was estimated with the Saito-Foley (SF) method [47] using BELMaster7 software (MicrotracBEL Corp., Osaka, Japan; ver.7.0.18.8). The adsorption sectional area of Ar at $87 \mathrm{~K}$ was $0.1420 \mathrm{~nm}^{2}$. These results are listed in Table 1 (see also Figures S1 and S2 in the Supplementary Materials).

Table 1. Physicochemical properties of catalysts used.

\begin{tabular}{|c|c|c|c|c|}
\hline Entry & Catalyst ${ }^{a}$ & $\begin{array}{c}\mathrm{S}_{\mathrm{BET}} b \\
\left(\mathrm{~m}^{2} \mathrm{~g}^{-1}\right)\end{array}$ & $\begin{array}{c}\text { Average Pore Size } b \\
(\mathrm{~nm})\end{array}$ & $\begin{array}{c}\text { Acid Amount } \\
\left(\mathrm{mmol} \mathrm{g}^{-1}\right)\end{array}$ \\
\hline 1 & Beta (25) & 494 & 0.69 & 0.37 \\
\hline 2 & Beta (42.2) & 639 & 0.68 & 0.42 \\
\hline 3 & Beta (104) & 613 & 0.71 & 0.24 \\
\hline 4 & Beta (150) & 607 & 0.73 & 0.20 \\
\hline 5 & Beta (440) & 571 & 0.71 & 0.076 \\
\hline 6 & Beta (1700) & 565 & 0.69 & 0.038 \\
\hline 7 & ZSM-5 (90) & 421 & 0.60 & 0.28 \\
\hline 8 & $\begin{array}{c}\text { Mordenite } \\
\quad(18.3)\end{array}$ & 479 & 0.57 & $>0.65$ \\
\hline 9 & Y (5.6) & 651 & 0.72 & 0.38 \\
\hline 10 & $\begin{array}{c}\mathrm{SiO}_{2}-\mathrm{Al}_{2} \mathrm{O}_{3} \\
\text { (2.1) }\end{array}$ & 305 & $\mathrm{~N} / \mathrm{A}$ & 0.42 \\
\hline
\end{tabular}

\footnotetext{
${ }^{a}$ Calcined at $823 \mathrm{~K}$ for $5 \mathrm{~h}$; the numbers in parentheses are the $\mathrm{SiO}_{2} / \mathrm{Al}_{2} \mathrm{O}_{3}$ ratios. ${ }^{b}$ Determined by Ar adsorption. $\mathrm{S}_{\mathrm{BET}}$ : a specific surface area determined by the Brunauer-Emmett-Teller theory. ${ }^{c}$ Estimated by $\mathrm{NH}_{3}$-temperature programmed desorption $\left(\mathrm{NH}_{3}-\mathrm{TPD}\right)$ analysis.
}

To ascertain the acidity of these samples, $\mathrm{NH}_{3}$-TPD was performed using Belcat II (MicrotracBEL Corp., Osaka, Japan). The sample (100 mg) was pretreated at $823 \mathrm{~K}$ for $1 \mathrm{~h}$ under an He flow before undergoing $\mathrm{NH}_{3}$ adsorption at $373 \mathrm{~K}$. Thereafter, the vapor treatments were performed three times at $373 \mathrm{~K}$ under an He flow. The $\mathrm{NH}_{3}$ desorption was monitored using mass $(m / e=16)$ for the temperature range $373-873 \mathrm{~K}$ at a ramping rate at $10 \mathrm{~K} \mathrm{~min}^{-1}$ and $873 \mathrm{~K}$ for $20 \mathrm{~min}$ (const.). The obtained profiles are described in Figure 2. Zeolite beta $\left(\mathrm{SiO}_{2} / \mathrm{Al}_{2} \mathrm{O}_{3}=150\right.$ ) had a single peak at around $630 \mathrm{~K}$ (acid amount: $0.20 \mathrm{mmol} \mathrm{g}^{-1}$ ) whereas ZSM-5 showed a peak at around $680 \mathrm{~K}$ (acid amount: $0.28 \mathrm{mmol}$ $\mathrm{g}^{-1}$ ); in other words, the latter possessed a greater abundance and stronger acid sites. Mordenite 
exhibited humped peaks at $519 \mathrm{~K}$ and $800 \mathrm{~K}$ (acid amount: $>0.65 \mathrm{mmol} \mathrm{g}^{-1}$ in total). Note that a further higher temperature in $\mathrm{NH}_{3}$-TPD seemed to be required to ascertain the full acidic nature in mordenite. However, application of such experimental conditions was limited because the calcination temperature was $823 \mathrm{~K}$ in this study. Zeolite $\mathrm{Y}$ and normal $\mathrm{SiO}_{2}-\mathrm{Al}_{2} \mathrm{O}_{3}$ gave a single peak at 582 $\mathrm{K}$ (acid amount: $0.38 \mathrm{mmol} \mathrm{g}^{-1}$ ) and a broad peak with the top of the peak at $557 \mathrm{~K}$ (acid amount: $0.42 \mathrm{mmol} \mathrm{g}^{-1}$ ), respectively. The $\mathrm{NH}_{3}$-TPD profiles for various zeolite beta samples with different $\mathrm{SiO}_{2} / \mathrm{Al}_{2} \mathrm{O}_{3}$ ratios are also shown in Figure $2 \mathrm{~b}$. The fundamental understanding is that a decrease in the $\mathrm{SiO}_{2} / \mathrm{Al}_{2} \mathrm{O}_{3}$ ratio would lead to an increase in the acid amounts of the zeolite [48,49]. However, the peak area for $\mathrm{SiO}_{2} / \mathrm{Al}_{2} \mathrm{O}_{3}=25$ (corresponding acid amount: $0.37 \mathrm{mmol} \mathrm{g}^{-1}$ ) was a little smaller than that for $\mathrm{SiO}_{2} / \mathrm{Al}_{2} \mathrm{O}_{3}=42.2$ (ibid.: $0.42 \mathrm{mmol} \mathrm{g}^{-1}$ ). From the viewpoint of the XRD patterns (Figure 1b) and pore size distribution (Figure S2), it was found that the crystallinity and pore volume of zeolite beta for $\mathrm{SiO}_{2} / \mathrm{Al}_{2} \mathrm{O}_{3}=25$ seemed to be slightly poorer than those of the other zeolite beta samples. Accordingly, we suppose that the BEA crystal imperfection in the case of $\mathrm{SiO}_{2} / \mathrm{Al}_{2} \mathrm{O}_{3}=25$ can lead to such disordering in the peak area in $\mathrm{NH}_{3}$-TPD, i.e., the acid amount, between $\mathrm{SiO}_{2} / \mathrm{Al}_{2} \mathrm{O}_{3}$ $=25$ and 42.2. Estimated acid amounts for all samples are listed in Table 1 .
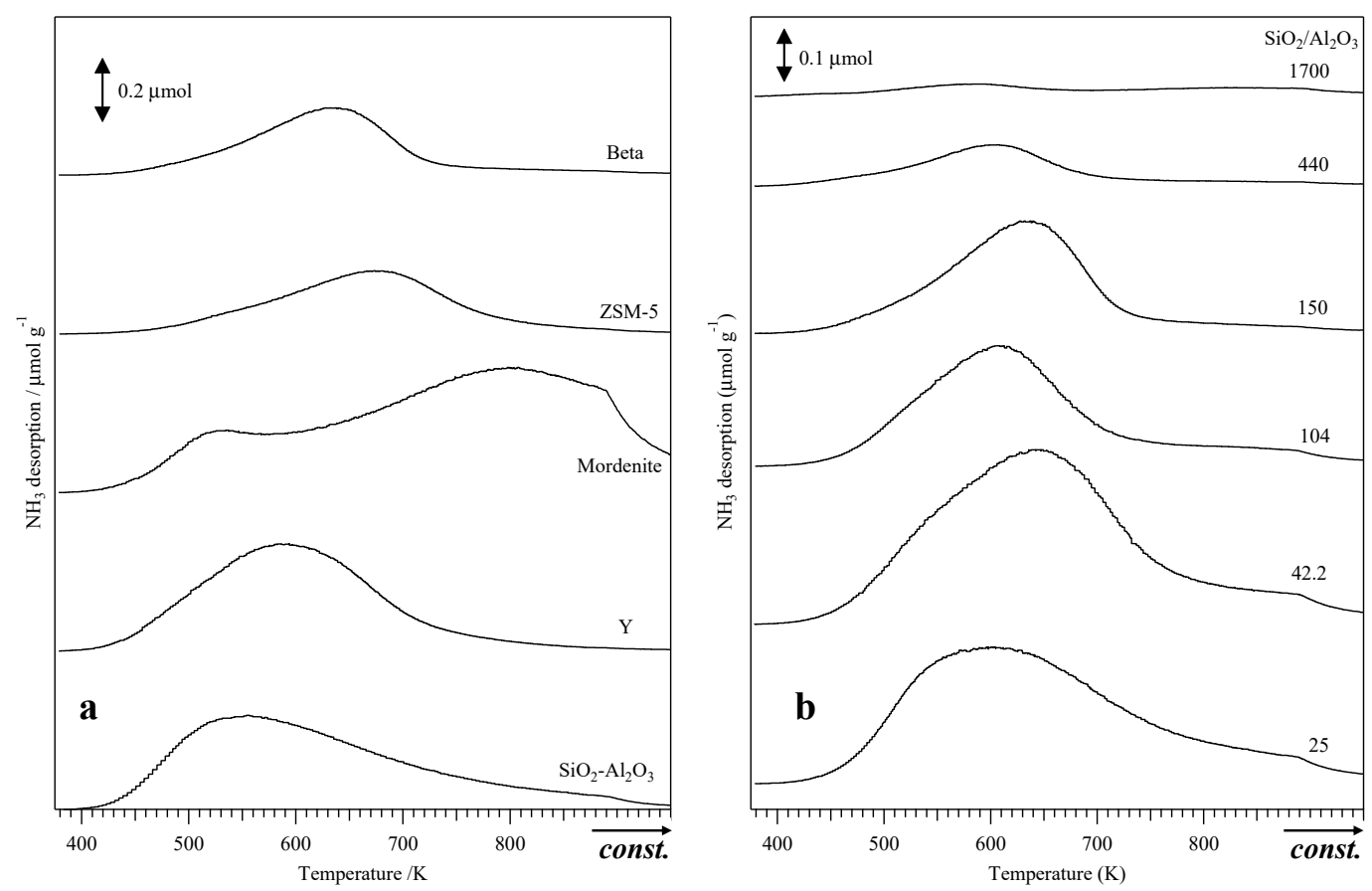

Figure 2. $\mathrm{NH}_{3}$-temperature programed desorption ( $\mathrm{NH}_{3}$-TPD) of (a) four types of reference zeolites and normal $\mathrm{SiO}_{2}-\mathrm{Al}_{2} \mathrm{O}_{3}$ and (b) zeolite betas composed with various $\mathrm{SiO}_{2} / \mathrm{Al}_{2} \mathrm{O}_{3}$ ratios.

\subsection{Reactivity among Different Zeolite Structures}

Figure 3 shows the time-based reaction progress of the hydroxymethylation of furfural with aqueous formaldehyde towards HMF production with zeolite beta, ZSM-5, mordenite, zeolite $\mathrm{Y}$, and normal $\mathrm{SiO}_{2}-\mathrm{Al}_{2} \mathrm{O}_{3}$. Zeolite $\mathrm{Y}$ and normal $\mathrm{SiO}_{2}-\mathrm{Al}_{2} \mathrm{O}_{3}$ were inactive for $\mathrm{HMF}$ production. Linear increases in HMF yield were observed for ZSM-5 and mordenite. Notably, only zeolite beta had a significant impact on HMF production with a high conversion value (see Figure S3). The best catalyst studied for the reaction of furfural with a formaldehyde aqueous solution was zeolite beta $\left(\mathrm{SiO}_{2} / \mathrm{Al}_{2} \mathrm{O}_{3}\right.$ $=150$ ), which afforded the highest HMF yield of $29 \%$ with $82 \%$ conversion of furfural at $6 \mathrm{~h}$ in the batch reactor system. 


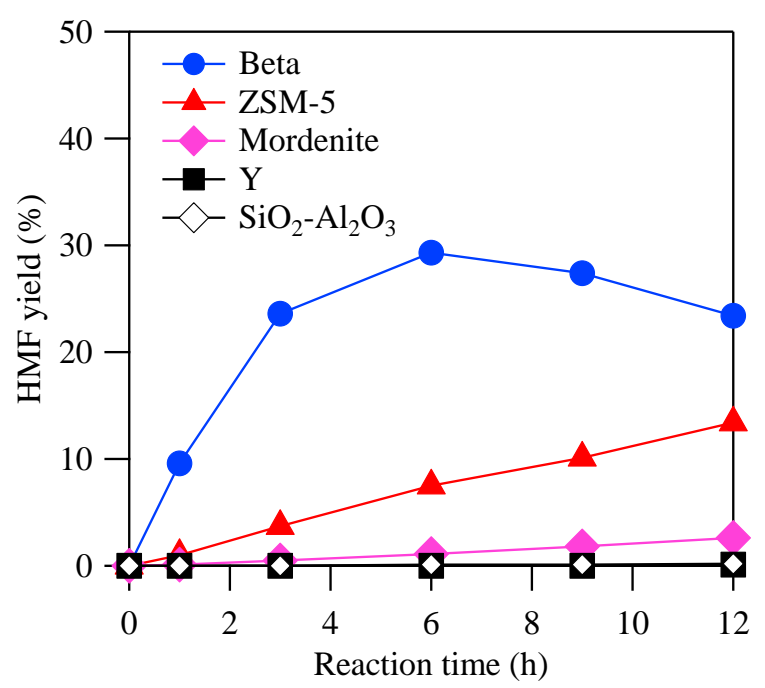

Figure 3. Time-based reaction progression of the hydroxymethylation of furfural towards HMF among four zeolites and normal $\mathrm{SiO}_{2}-\mathrm{Al}_{2} \mathrm{O}_{3}$ in a batch reactor. Reaction conditions: furfural ( $\left.1 \mathrm{mmol}\right)$, formalin $(5 \mathrm{~mL})$, catalyst $(200 \mathrm{mg})$, temperature $(363 \mathrm{~K})$, stirring $(500 \mathrm{rpm})$.

Because these four types of zeolite were composed of different $\mathrm{SiO}_{2} / \mathrm{Al}_{2} \mathrm{O}_{3}$ ratios in this study, a simple discussion of structural impacts on the hydroxymethylation of furfural towards HMF in aqueous formaldehyde was difficult to achieve. However, interesting phenomena for zeolite beta were also observed in the flow reactor system. Figure 4 shows the results for the application of a continuous flow reactor system over the four types of zeolite catalysts for the hydroxymethylation of furfural towards HMF. As shown in Figure 4a, gradual decreases in furfural conversion value were detected for all zeolite samples during the progress of the flow reaction. From the viewpoint of the catalytic behavior affording HMF (yield) shown in Figure $4 \mathrm{~b}$, however, zeolite beta showed significantly different behavior. In the case of zeolite beta only, a gradual increase and constant yield were monitored within $3.5 \mathrm{~h}$ in the flow reaction, though the other three zeolites gave an inactive and/or decreasing yield for HMF. Such unique behavior of zeolite beta also appeared for various $\mathrm{SiO}_{2} / \mathrm{Al}_{2} \mathrm{O}_{3}$ cases (vide infra). Note that the initial induction period detected in a flow reactor system owes itself to the pelletizing treatment of the powder sample. Accordingly, the textural specialty of zeolite beta is an attractive subject of attention, even though the different $\mathrm{SiO}_{2} / \mathrm{Al}_{2} \mathrm{O}_{3}$ ratios were used for discussion of reactivity among four types of zeolite samples.
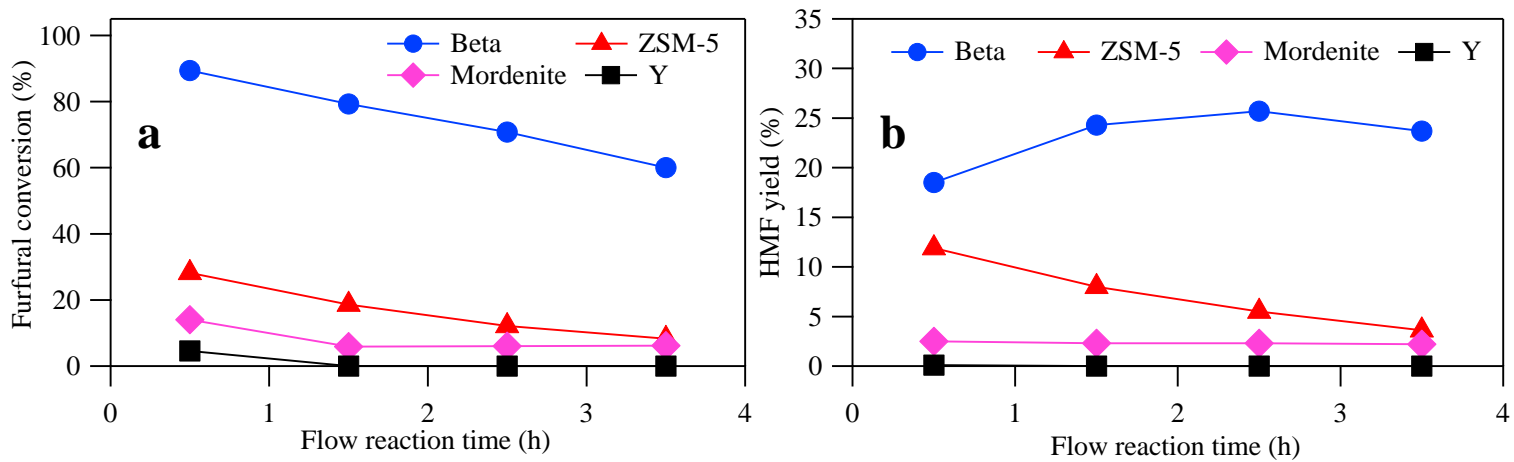

Figure 4. Time-based reaction for HMF production in a flow reactor using four different types of zeolites. Reaction conditions: furfural $(10 \mathrm{mmol})$, formalin $(50 \mathrm{~mL})$, catalyst $(500 \mathrm{mg})$, temperature $(363 \mathrm{~K})$, flow rate $\left(0.2 \mathrm{~mL} \mathrm{~min}^{-1}\right)$.

It was noted that zeolite beta, mordenite, and zeolite $Y$ had large-pore structures of $\sim 5.6 \AA \times 7.6 \AA$, $\sim 6.5 \AA \times 7.0 \AA$, and $\sim 7.4 \AA \times 7.4 \AA$, respectively, whereas ZSM-5 possessed a medium-pore structure 
of $\sim 5.1 \AA \times 5.6 \AA[50,51]$. On the basis of the present Ar adsorption analytical approach, mordenite exhibited a middle pore diameter of $5.7 \AA$ (Figure S1b), which was a smaller value than that mentioned above. Because mordenite is constructed with two types of ring, these being an 8-membered ring $(\sim 3.4 \AA \times 4.8 \AA)$ and a 12-membered ring $(\sim 6.5 \AA \times 7.0 \AA)$, such differences were expected. ZSM-5 is a 10 -membered ring zeolite, whereas zeolite beta and zeolite $Y$ are 12-membered ring zeolites. According to these properties, the size sensitivity and/or topology derived from each zeolite type would have scarcely contributed to the differences in reactivity for the target reaction. However, it was interesting to observe that the conversion values of furfural dramatically changed across the different zeolites (vide supra). There has been some discussion on the importance of acidity, i.e. the Brønsted/Lewis amount, to try to explain the different reactivities obtained for various types of zeolites in the presence of water $[52,53]$.

\subsection{Reusability of Zeolite Beta}

The reusability of zeolite beta $\left(\mathrm{SiO}_{2} / \mathrm{Al}_{2} \mathrm{O}_{3}=150\right)$ was investigated in a batch reactor. After the present reaction, the reaction media was centrifuged, and then the spent powder catalyst was washed with $0.5 \mathrm{~L}$ water and dried at $383 \mathrm{~K}$ overnight. Thereafter, the next recycling run was performed after re-calcination treatment at $823 \mathrm{~K}$ for $5 \mathrm{~h}$. Because weight loss of catalyst powder could not be prohibited during the catalyst correction and reactivation procedures, different scales were applied for the recycling tests (see Table S1). As shown in Figure 5, high reusability for the above three recycling runs was achieved with zeolite beta. It should be noted that re-calcination treatment was necessary because a significant color change from white to dark gray after reaction occurred, i.e., strong carbon depositions onto the catalyst surface were expected during the reaction (see Figures S4 and S5). In the high performance liquid chromatography (HPLC) chart, some unidentified peaks were detected (Figure S6). However, the gas chromatography-time of flight mass (GC-TOFMS) spectrometry (JEOL Ltd., Tokyo, Japan; AccuTOFGCx) of the reaction mixture could not identify any appropriate side reactions, such as the self-resinification of furfural $[45,54]$ and the dimerization of as-produced HMF $[55,56]$, for the present situation; some of these products might be trapped on/in the zeolite, leading to color changes during the reaction.

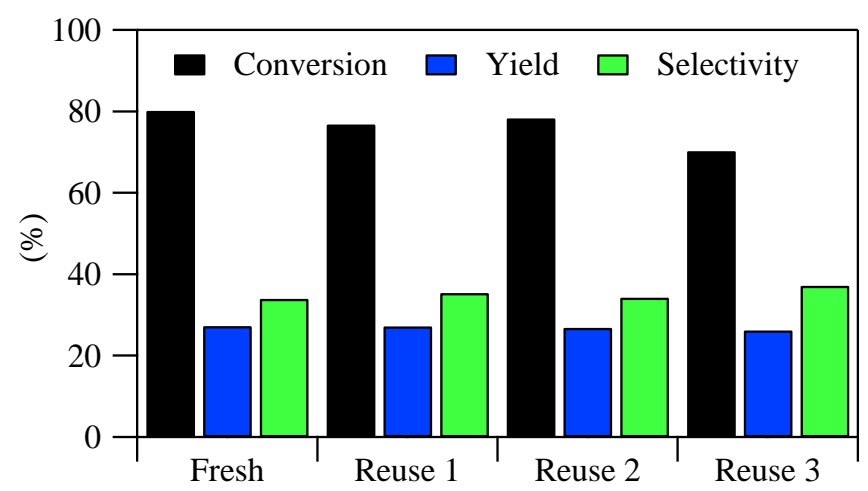

Figure 5. Recycling tests on the hydroxymethylation of furfural towards HMF over zeolite beta in a batch reactor. Reaction conditions: furfural (1-3 mmol), formalin (5-15 mL), catalyst (600-200 mg), temperature $(363 \mathrm{~K})$, time $(6 \mathrm{~h})$, stirring $(500 \mathrm{rpm})$. The catalyst was re-calcined at $823 \mathrm{~K}$ before each reuse.

\subsection{Effect of $\mathrm{SiO}_{2} / \mathrm{Al}_{2} \mathrm{O}_{3}$ Ratio on Zeolite Beta}

The effect of the $\mathrm{SiO}_{2} / \mathrm{Al}_{2} \mathrm{O}_{3}$ ratio on the target reaction was evaluated using fine zeolite beta samples fabricated with different $\mathrm{SiO}_{2} / \mathrm{Al}_{2} \mathrm{O}_{3}$ ratios. Figure 6 shows the time-based reaction progress of the hydroxymethylation of furfural towards $\mathrm{HMF}$ among zeolite beta samples composed of different $\mathrm{SiO}_{2} / \mathrm{Al}_{2} \mathrm{O}_{3}$ ratios in a batch reactor. Corresponding alterations of conversion and yield are also shown in Figure S7. Interestingly, $\mathrm{SiO}_{2} / \mathrm{Al}_{2} \mathrm{O}_{3}$ strongly influenced the reaction progress for the target reaction 
(Figure 6a). An increase in the $\mathrm{SiO}_{2} / \mathrm{Al}_{2} \mathrm{O}_{3}$ ratio from 25 to 42.2 led to a great increase in $\mathrm{HMF}$ yield, while similar progress of the reaction was obtained for the range 42.4-150. Thereafter, it seemed to gradually diminish in the cases from 440 to 1700 . The highest yield of $31.6 \%$ with a $67.9 \%$ conversion rate was detected at $12 \mathrm{~h}$ during the reaction for $\mathrm{SiO}_{2} / \mathrm{Al}_{2} \mathrm{O}_{3}=104$.
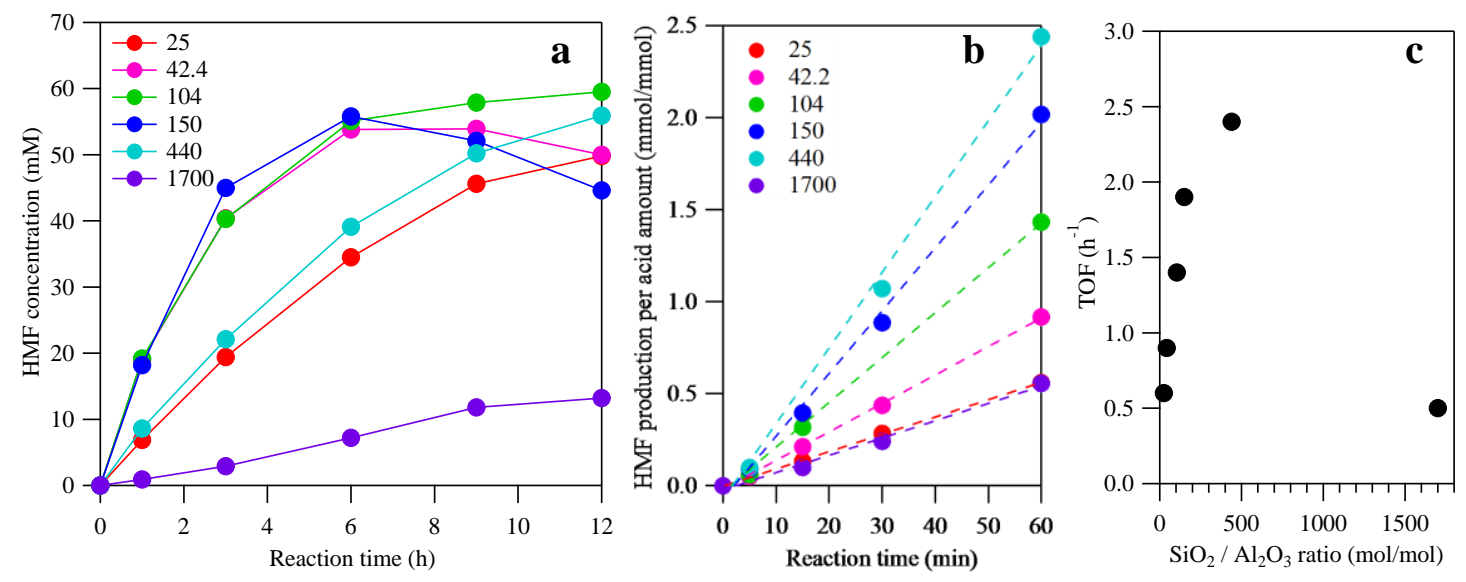

Figure 6. Time-based reaction progression of the hydroxymethylation of furfural to HMF among zeolite beta samples composed of different $\mathrm{SiO}_{2} / \mathrm{Al}_{2} \mathrm{O}_{3}$ ratios in a batch reactor: (a) HMF concentration and (b) initial rate for HMF production per acid amount. (c) Plot of turnover frequency (TOF) values as a function of $\mathrm{SiO}_{2} / \mathrm{Al}_{2} \mathrm{O}_{3}$ ratio on the basis of the dashed lines in (b) which represent the linear approximation results. Reaction conditions: furfural $(1 \mathrm{mmol})$, formalin $(5 \mathrm{~mL})$, catalyst $(200 \mathrm{mg})$, temperature (363 K), stirring (500 rpm).

To further discuss the details of the differences in reactivity derived from the $\mathrm{SiO}_{2} / \mathrm{Al}_{2} \mathrm{O}_{3}$ ratios, the initial rates of the reaction per acid amount and the TOF values were plotted in Figure $6 \mathrm{~b}, \mathrm{c}$, respectively. It can be clearly observed that the $\mathrm{SiO}_{2} / \mathrm{Al}_{2} \mathrm{O}_{3}$ ratio was greatly associated with the reactivity of the target reaction. The reactivity had been heightened by increasing the $\mathrm{SiO}_{2} / \mathrm{Al}_{2} \mathrm{O}_{3}$ ratio from 25 to 440 . The highest TOF value leached at $2.4 \mathrm{~h}^{-1}$, which was four times higher than that obtained using $\mathrm{SiO}_{2} / \mathrm{Al}_{2} \mathrm{O}_{3}=25$. In addition, a significantly large $\mathrm{SiO}_{2} / \mathrm{Al}_{2} \mathrm{O}_{3}$ value (1700) produced a drastic decrease in the TOF value, giving a value of $0.5 \mathrm{~h}^{-1}$.

In previous studies on zeolite catalysis, many researchers have insisted on the importance of the hydrophobic/hydrophilic nature of zeolites within the catalysis $[57,58]$. To anticipate the association of surface affinity with water, the main reaction media, the $\mathrm{H}_{2} \mathrm{O}(18.2 \mathrm{k} \Omega \cdot \mathrm{cm})$ adsorption isotherm at $298 \mathrm{~K}$ was attempted using BELSORP-max. (BEL JAPAN, INC., Osaka, Japan). The samples (100 mg) were pretreated at $573 \mathrm{~K}$ for $6 \mathrm{~h}$ under vacuum before being measured. The adsorption sectional area of $\mathrm{H}_{2} \mathrm{O}$ at $298 \mathrm{~K}$ was $0.1250 \mathrm{~nm}^{2}$. Figure 7 shows the plot of the monolayer adsorption capacity density, which is the monolayer water adsorption capacity value $\left(v_{\mathrm{m}}\right)\left(\mathrm{cm}^{3}(\mathrm{STP}) \mathrm{g}^{-1}\right)$ divided by a specific surface area against $\mathrm{Ar}\left(\mathrm{m}^{2} \mathrm{~g}^{-1}\right)$ as a function of the $\mathrm{SiO}_{2} / \mathrm{Al}_{2} \mathrm{O}_{3}$ ratio in zeolite beta. According to previous papers $[46,59]$, it was well-known that delamination treatment usually enhances the hydrophobic nature of zeolites. In fact, the $\mathrm{SiO}_{2} / \mathrm{Al}_{2} \mathrm{O}_{3}$ ratio for zeolite beta involved the monolayer water adsorption capacity, and the $\mathrm{SiO}_{2} / \mathrm{Al}_{2} \mathrm{O}_{3}=440$ ratio which exhibited the highest TOF value (vide superior) possessed the strongest hydrophobic nature among the zeolite beta samples used in this study. Note that the difference in tendencies observed in the cases of lower/higher $\mathrm{SiO}_{2} / \mathrm{Al}_{2} \mathrm{O}_{3}(=25$ and 1700) detected in Figure 7 would be owing to the poor crystallinity of the zeolite and/or the presence of extra $\mathrm{SiO}_{2}$ or $\mathrm{Al}_{2} \mathrm{O}_{3}$ species. A similar tendency between adsorption capacity and $\mathrm{SiO}_{2} / \mathrm{Al}_{2} \mathrm{O}_{3}$ ratio has been observed in the case of mordenite in a previous paper [60]. Accordingly, hydrophobicity was considered to be the one of key factors in accelerating the target reaction. It is notable that Moreau et al. also insisted that the hydrophobic character in mordenite was a predominant factor in the activity of hydroxymethylation of furfuryl alcohol by aqueous formaldehyde because the adsorption of organic substrates onto the catalyst in water as solvent determined the reaction constant for the reaction [46]. 
However, there still remains an open question about whether the relationship between the TOF value and the monolayer adsorption capacity density did not make a linear contribution. It is supposed that determination of the actual acid sites working in water solvent, e.g., the impact of water tolerance on Brønsted/Lewis acidity, would be helpful for further understanding the mechanism of zeolite beta-catalyzed hydroxymethylation of furfural to HMF with aqueous formaldehyde as a dual solvent and reagent. Notably, applications of various zeolite betas for the flow reactor system were also capable and showed good stability of HMF yield (see Figure S8).

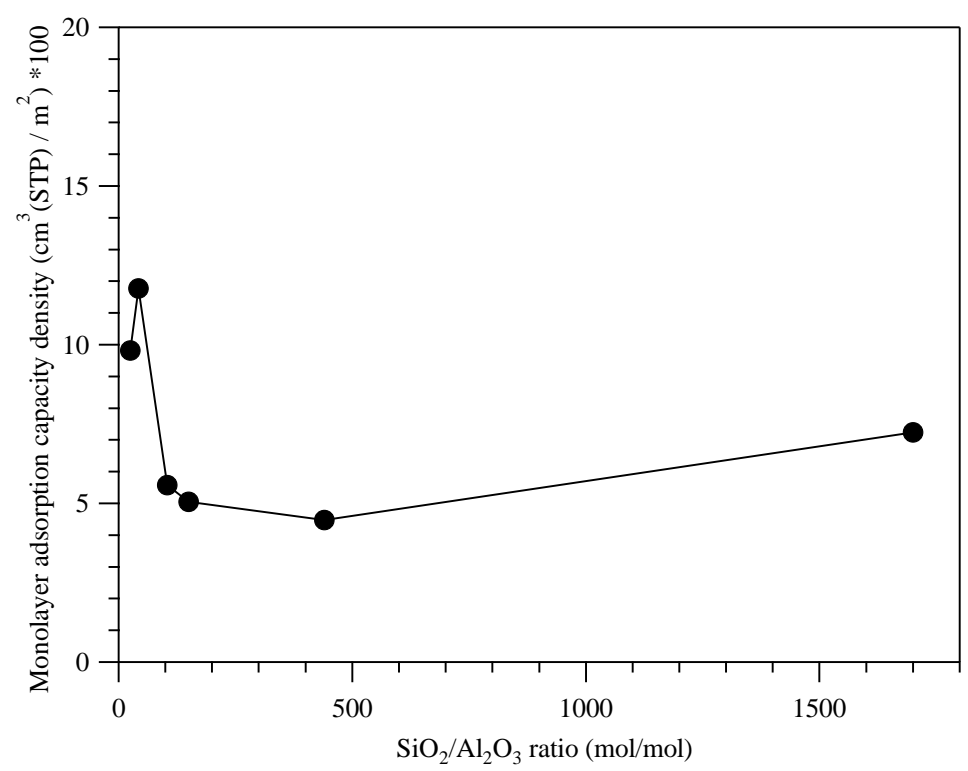

Figure 7. Monolayer adsorption capacity density as a function of $\mathrm{SiO}_{2} / \mathrm{Al}_{2} \mathrm{O}_{3}$ ratio with zeolite beta. STP: standard ambient temperature and pressure.

\section{Materials and Methods}

\subsection{Batch Reactor System}

The reaction was performed in a Schlenk glass flask attached to a condensation cooler. As a general procedure, first, $37 \%$ aqueous formaldehyde solution (stabilized with $5-10 \%$ methanol, Wako Pure Chemical Ind. Ltd., Osaka, Japan) $(5 \mathrm{~mL})$ and solid catalyst $(200 \mathrm{mg})$ were mixed well under vigorous stirring $(500 \mathrm{rpm})$ at $363 \mathrm{~K}$. Thereafter, the substrate of furfural $(1 \mathrm{mmol})$ without purification treatment (Acros Organic, Geel, Belgium; 99\% purity) was injected into the above mixture to initiate the target reaction. Then, after $12 \mathrm{~h}$ of reaction, the catalyst was filtered off with a Milex syringe filter $(0.20 \mu \mathrm{m})$ (Merck, Darmstadt, Germany) and the obtained filtrate was analyzed using an HPLC equipped with a refractive index (RI) detector (Waters 2414). The column was an Aminex HPX-87H (Bio-Rad Laboratories Inc., Hercules, CA, USA) under $10 \mathrm{mM} \mathrm{H}_{2} \mathrm{SO}_{4}$ aq. flow $\left(0.5 \mathrm{~mL} \mathrm{~min}^{-1}\right)$. The retention times for HMF and furfural were $39.1 \mathrm{~min}$ and $60.0 \mathrm{~min}$, respectively. Conversion and yield values were estimated with the standard lines adjusted by each reference compound.

\subsection{Flow Reactor System}

The liquid flow reaction was examined with a simple flow reactor system (MCR-1000; EYELA, Tokyo, Japan). A powdered zeolite sample was pressed (40 kPa for $30 \mathrm{~min}$ ) into thin wafers, and then crushed and screened within a mesh size range of 26-42, before being installed into the reaction bed tube $(\varphi 5)$. The flow rate of the reaction mixture of furfural $(10 \mathrm{mmol})$ and formalin $(50 \mathrm{~mL})$ was $0.2 \mathrm{~mL}$ $\mathrm{min}^{-1}$ and the reaction was performed at $363 \mathrm{~K}$. The reactant was analyzed by HPLC using the same procedure mentioned above. 


\section{Conclusions}

In summary, four types of typical zeolites and normal $\mathrm{SiO}_{2}-\mathrm{Al}_{2} \mathrm{O}_{3}$ were tentatively compared with regard to their reactivity for the hydroxymethylation of furfural towards HMF in a batch reactor system and a flow reactor system. Interestingly, the beta-type zeolite was found to be a highly-active, reusable, and uniquely stable catalyst. The effect of the $\mathrm{SiO}_{2} / \mathrm{Al}_{2} \mathrm{O}_{3}$ ratio for the various zeolite beta samples was examined using reactivity (TOF), $\mathrm{NH}_{3}$-TPD, and water adsorption capacity. The zeolite beta composed of $\mathrm{SiO}_{2} / \mathrm{Al}_{2} \mathrm{O}_{3}=440$ gave the highest TOF value of $2.4 \mathrm{~h}^{-1}$ in the batch reactor system and it possessed a strong hydrophobic nature. According to these results, it may be suggested that hydrophobicity plays a crucial role in the hydroxymethylation of furfural towards HMF using an aqueous formaldehyde reagent. In comparison to our previous report, which focused on a sulfuric functionalized resin catalyst [42], we have observed that there are a variety of ways of constructing morphology / affinity-controlled zeolite fabrications. Therefore, novel catalysis derived from zeolite beta in this report is expected to open up new possibilities for future research on the designs of zeolite-catalyzed hydroxymethylations, and in particular, the upgrading of $\mathrm{C} 5$ to $\mathrm{C} 6$ furaldehydes in biorefinery.

Supplementary Materials: The following are available online at http:/ / www.mdpi.com/2073-4344/9/4/314/ s1, Figure S1: Pore size distributions of ZSM-5, mordenite, zeolite $\mathrm{Y}$, and normal $\mathrm{SiO}_{2}-\mathrm{Al}_{2} \mathrm{O}_{3}$ determined by Ar adsorption, Figure S2: Pore size distributions of zeolite beta with various $\mathrm{SiO}_{2} / \mathrm{Al}_{2} \mathrm{O}_{3}$ determined by $\mathrm{Ar}$ adsorption, Figure S3: Time-based reaction progression of furfural conversion for hydroxymethylation among four zeolites and normal $\mathrm{SiO}_{2}-\mathrm{Al}_{2} \mathrm{O}_{3}$ in a batch reactor, Table S1: Recycling experiments for the zeolite beta $\left(\mathrm{SiO}_{2} / \mathrm{Al}_{2} \mathrm{O}_{3}=150\right)$ in a batch reactor, Figure S4: T Photographs of (a) fresh and (b) spent zeolite beta catalyst $\left(\mathrm{SiO}_{2} / \mathrm{Al}_{2} \mathrm{O}_{3}=150\right)$, Figure S5: TG-DTA curves of spent zeolite beta $\left(\mathrm{SiO}_{2} / \mathrm{Al}_{2} \mathrm{O}_{3}=150\right)$ in a batch reaction, Figure S6: Example of HPLC chromatograph for the hydroxymethylation of furfural to HMF in aqueous formaldehyde over zeolite beta, Figure S7: Time-based reaction progression of the hydroxymethylation of furfural to HMF among zeolite beta samples composed of different $\mathrm{SiO}_{2} / \mathrm{Al}_{2} \mathrm{O}_{3}$ ratios in a batch reactor: (a) furfural conversion and (b) HMF yield, Figure S8: Time-based reaction for HMF production in a flow reactor using $\mathrm{f}$ zeolite beta samples composed of various $\mathrm{SiO}_{2} / \mathrm{Al}_{2} \mathrm{O}_{3}$ ratios: (a) furfural conversion and (b) $\mathrm{HMF}$ yield.

Author Contributions: Conceptualization, S.N.; methodology, S.N. and A.S.; formal analysis, S.N. and A.S.; investigation, S.N. and A.S.; resources, S.N. and A.S.; data curation, S.N. and A.S.; writing-original draft preparation, S.N.; writing — review and editing, S.N.; visualization, S.N.; supervision, S.N.; project administration, S.N.; funding acquisition, S.N.

Funding: This work was supported by JSPS KAKENHI for Young Scientists (A) (grant no. 17H04966), Japan.

Acknowledgments: The authors would like to thank Prof. K. Ebitani (JAIST) for his encouragement of this research and Dr. D. Mott (Tohoku Univ.) for his careful reading of the manuscript.

Conflicts of Interest: The authors declare that they have no competing financial interest.

\section{References}

1. Van Putten, R.J.; van der Waal, J.C.; de Jong, E.; Rasrendra, C.B.; Heeres, H.J.; de Vries, J.G. Hydroxymethylfurfural, A Versatile Platform Chemical Made from Renewable Resources. Chem. Rev. 2013, 113, 1499-1597. [CrossRef] [PubMed]

2. Isikgor, F.H.; Becer, C.R. Lignocellulosic biomass: A sustainable platform for the production of bio-based chemicals and polymers. Polym. Chem. 2015, 6, 4497-4559. [CrossRef]

3. Delidovich, I.; Hausoul, P.J.C.; Deng, L.; Pfutzenreuter, R.; Rose, M.; Palkovits, R. Alternative Monomers Based on Lignocellulose and Their Use for Polymer production. Chem. Rev. 2016, 116, 1540-1599. [CrossRef] [PubMed]

4. Kobayashi, H.; Fukuoka, A. Synthesis and utilization of sugar compounds derived from lignocellulosic biomass. Green Chem. 2013, 15, 1740-1763. [CrossRef]

5. Nishimura, S.; Ebitani, K. Selective Oxidation of Biomass-derived Alcohols with Supported Metal Catalysts. J. Jpn. Petroleum Inst. 2017, 60, 72-84. [CrossRef]

6. Lange, J.P.; van der Heide, E.; van Buijtenen, J.; Price, R. Furfural—A Promising Platform for Lignocellulosic biofuels. ChemSusChem 2012, 5, 150-166. [CrossRef] [PubMed] 
7. Xu, S.; Zhou, P.; Zhang, Z.; Yang, C.; Zhang, B.; Deng, K.; Bottle, S.; Zhu, H. Selective Oxidation of 5-Hydroxymethylfurfural to 2,5-Furandicarboxylic Acid using $\mathrm{O}_{2}$ and a Photocatalyst of Cothioporphyrazine Bonded to g-C $\mathrm{C}_{3} \mathrm{~N}_{4}$. J. Am. Chem. Soc. 2017, 139, 14775-14782. [CrossRef]

8. Gupta, N.K.; Nishimura, S.; Takagaki, A.; Ebitani, K. Hydrotalcite supported gold-nanoparticle-catalyzed highly efficient base-free aqueous oxidation of 5-hydroxymethylfurfural into 2,5-fudandicarboxylic acid under atmospheric oxygen pressure. Green Chem. 2011, 13, 824-827. [CrossRef]

9. Yuan, Z.; Liu, B.; Zhou, P.; Zhang, Z.; Chi, Q. Aerobic oxidation of biomass-derived 5-hydrxymtehylfurfural to 2,5-diformylfuran with cesium-doped manganese dioxide. Catal. Sci. Techonol. 2018, 8, 4430-4439. [CrossRef]

10. Takagaki, A.; Takahashi, M.; Nishimura, S.; Ebitani, K. One-pot synthesis of 2,5-diformylfuran from carbohydrate derivatives by sulfonated resin and hydrotalcite-supported ruthenium catalysts. ACS Catal. 2011, 1, 1562-1565. [CrossRef]

11. Perret, N.; Grigoropoulos, A.; Zanella, M.; Manning, T.D.; Claridge, J.B.; Rosseinsky, M.J. Catalytic Response and Stability of Nickel/Alumina for the Hydrogenation of 5-Hydroxymethylfurfural in water. ChemSusChem 2016, 8, 521-531. [CrossRef] [PubMed]

12. Ohyama, J.; Hayashi, Y.; Ueda, K.; Yamamoto, Y.; Arai, S.; Satsuma, A. Effect of $\mathrm{FeO}_{\mathrm{x}}$ modification of $\mathrm{Al}_{2} \mathrm{O}_{3}$ on its supported Au catalyst for hydrogenation of 5-hydroxymethylfurfural. J. Phys. Chem. C 2016, 120, 15129-15136. [CrossRef]

13. Roman-Leshkov, Y.; Barrett, C.J.; Liu, Z.Y.; Dumesic, J.A. Production of dimethylfuran for liquid fuels from biomass-derived carbonhydrates. Nature 2007, 447, 982-985. [CrossRef]

14. Thananatthanachon, T.; Rauchfuss, T.B. Efficient Production of the liquid fuel 2,5-Dimethylfuran from fructose using formic Acid as a reagent. Angew. Chem. Int. Ed. 2010, 49, 6616-6618. [CrossRef]

15. Nishimura, S.; Ikeda, N.; Ebitani, K. Selective hydrogenation of biomass-derived 5-hydroxymethylfurfural (HMF) to 2,5-dimethylfuran (DMF) under atomospheric hydrogen pressure over carbon supported PdAu bimetallic catalyst. Catal. Today 2014, 232, 89-98. [CrossRef]

16. Chandra, D.; Inoue, Y.; Sasase, M.; Kitano, M.; Bhaumik, A.; Kamata, K.; Hosono, H.; Hara, M. A high performance catalyst of shape-specific ruthenium nanoparticles for production pf primary amines by reductive amination of carbonyl compounds. Chem. Sci. 2018, 9, 5949-5956. [CrossRef]

17. Tuteja, J.; Choudhary, H.; Nishimura, S.; Ebitani, K. Direct synthesis of 1,6-hexanediol from HMF over a heterogeneous $\mathrm{Pd} / \mathrm{ZrP}$ catalyst using formic acid as hydrogen source. ChemSusChem 2014, 7, 96-100. [CrossRef]

18. Weingarten, R.; Conner, W.C., Jr.; Huber, G.W. Production of levulinic acid from cellulose by hydrothermal decomposition combined with aqueous phase dehydration with a solid acid catalyst. Energy Environ. Sci. 2012, 5, 7559-7574. [CrossRef]

19. Son, P.A.; Nishimura, S.; Ebitani, K. Synthesis of levulinic acid from fructose using Amberlyst-15 as a solid acid catalyst. React. Kinet. Mech. Catal. 2012, 106, 185-192. [CrossRef]

20. Pupovac, K.; Palkovits, R. Cu/ $\mathrm{MgAl}_{2} \mathrm{O}_{4}$ as Bifunctional Catalyst for Aldol Condensation of 5-Hydroxymethylfurfural and selective Transfer Hydrogenation. ChemSusChem 2013, 6, 2103-2110. [CrossRef] [PubMed]

21. Buntara, T.; Noel, S.; Phua, P.H.; Melian-Cabrera, I.; de Vries, J.G. Caprolactam from Renewable Resources: Catalytic Conversion of 5-Hydroxymethylfurfural into Caprolactone. Angew. Chem. Int. Ed. 2011, 50, 7083-7087. [CrossRef]

22. Wozniak, B.; Spannenberg, A.; Li, Y.; Hinze, S.; de Vries, J.G. Cyclopentanone Derivatives from 5-Hydroxymethylfurfural via 1-Hydroxyhexane-2,5-dione as Intermediate. ChemSusChem 2018, 11, 356-359. [CrossRef]

23. Gomes, R.F.A.; Coelho, J.A.S.; Afonso, C.A.M. Direct Conversion of Activated 5-Hydroxymethylfurfural into d-Lactone-fused Cyclopentenones. ChemSusChem 2019, 12, 420-425. [CrossRef]

24. Gupta, N.K.; Fukuoka, A.; Nakajima, K. Metal-Free and Selective Oxidation of furfural to Furoic Acid with an N-heterocyclic Carbone Catalyst. ACS Sustain. Chem. Eng. 2018, 6, 3434-3442. [CrossRef]

25. Douthwaite, M.; Huang, X.; Iqbal, S.; Miedziak, P.J.; Brett, G.L.; Kondrat, S.A.; Edwards, J.K.; Sankar, M.; Knight, D.W.; Bethell, D.; et al. The controlled catalytic oxidation of furfural to furoic acid using $\mathrm{AuPd} / \mathrm{Mg}(\mathrm{OH})_{2}$. Catal. Sci. Technol. 2017, 7, 5284-5293. [CrossRef] 
26. Lopez-Asensio, R.; Cecilia, J.A.; Jimenez-Gomez, C.P.; Garcia-Sancho, C.; Moreno-Rost, R.; Maireles-Torres, P. Selective production of furfuryl alcohol from furfural by catalytic transfer hydrogenation over commercial aluminas. Appl. Catal. A Gen. 2018, 556, 1-9. [CrossRef]

27. Nishimura, S.; Shimura, T.; Ebitani, K. Transfer hydrogenation of furaldehydes with sodium phosphinate as a hydrogen source using Pd-supported alumina catalyst. J. Taiwan Inst. Chem. Eng. 2017, 79, 97-102. [CrossRef]

28. Gandarias, I.; Garcia-Fernandez, S.; Obregon, I.; Agirrezabal-Telleria, I.; Arias, P.L. Production of 2-methylfuran from biomass through an integrated biorefinery approach. Fuel Proc. Technol. 2018, 178, 336-343. [CrossRef]

29. Sitthisa, S.; An, W.; Resasco, D.E. Selective conversion of furfural to methylfuran over silica-supported Ni-Fe bimetallic catalysts. J. Catal. 2011, 284, 90-101. [CrossRef]

30. Komanoya, T.; Kinemura, T.; Kita, K.; Kamata, K.; Hara, M. Electronic effect of ruthenium nanoparticles on efficient reductive amination of carbonyl compounds. J. Am. Chem. Soc. 2017, 139, 11493-11499. [CrossRef]

31. Nishimura, S.; Mizuhori, K.; Ebitani, K. Reductive amination of furfural toward furfurylamine with aqueous ammonia under hydrogen over Ru-supported catalyst. Res. Chem. Intermed. 2016, 42, 19-30. [CrossRef]

32. Liu, S.; Amada, Y.; Tamura, M.; Nakagawa, Y.; Tomishige, K. Performance and characterization of rhenium-modified Rh-Ir alloy catalyst for one-pot conversion of furfural into 1,5-oentandiol. Catal. Sci. Technol. 2014, 4, 2535-3549. [CrossRef]

33. Lee, J.; Burt, S.P.; Carrero, C.A.; Alba-Rubio, A.C.; Ro, I.; O’Neil, B.J.; Kim, H.J.; Jackson, D.H.K.; Kuech, T.F.; Hermans, I.; et al. Stabilizating cobalt catalyst for aqueous-phase reactions by strong metal-support interaction. J. Catal. 2015, 330, 19-27. [CrossRef]

34. Choudhary, H.; Nishimura, S.; Ebitani, K. Highly efficient aqueous oxidation of furfural to succinic acid using reusable heterogeneous acid catalyst with hydrogen peroxide. Chem. Lett. 2012, 41, 409-411. [CrossRef]

35. Yang, J.; Li, N.; Li, G.; Wang, W.; Wang, A.; Wang, X.; Cong, Y.; Zhang, T. Solvent-Free Synthesis of $\mathrm{C}_{10}$ and $C_{11}$ Branched Alkanes from Furfural and Methyl Isobutyl Ketone. ChemSusChem 2013, 6, 1149-1152. [CrossRef] [PubMed]

36. Xu, W.; Xia, Q.; Zhang, Y.; Guo, Y.; Wang, Y.; Lu, G. Effective Production of Octane from Biomass Derivatives under Mild Conditions. ChemSusChem 2011, 4, 1758-1761. [CrossRef]

37. Shirotori, M.; Nishimura, S.; Ebitani, K. One-Pot Synthesis of Furfural Derivatives from Pentoses using Solid Acid and Base Catalysts. Catal. Sci. Technol. 2014, 4, 971-978. [CrossRef]

38. Nunes, J.P.M.; Afonso, C.A.M.; Caddick, S. Synthesis of 2,4-bifunctionalized cyclopentenones from 2-furaldehyde. RSC Adv. 2013, 3, 14975-14978. [CrossRef]

39. Nardi, M.; Costanzo, P.; Nino, A.D.; Gioia, M.L.D.; Olivito, F.; Sindona, G.; Procopio, A. Water excellent solvent for the synthesis of bifunctionalized cyclopentenones from furfuram. Green Chem. 2017, 19, 5403-5411. [CrossRef]

40. Gioia, M.L.D.; Nardi, M.; Costanzo, P.; Nino, A.D.; Maiuolo, L.; Oliverio, M.; Procopio, A. Biorenewable Deep Eutectic Solvent for Selective and Scalable Conversion of Furfural into Cyclopenenone Derivatives. Molecules 2018, 23, 1891. [CrossRef]

41. Koh, P.F.; Wang, P.; Huang, J.M.; Loh, T.P. Biomass derived furfural-based facile synthesis of protected (2S)-phenyl-3-piperidone, a common intermediate for many drugs. Chem. Commun. 2014, 50, 8324-8327. [CrossRef]

42. Nishimura, S.; Shibata, A.; Ebitani, K. Direct Hydroxymethylation of Furaldehydes with Aqueous Formaldehyde over a Reusable Sulfuric Functionalized Resin Catalyst. ACS Omega 2018, 3, 5988-5993. [CrossRef]

43. Lecomte, J.; Finiels, A.; Geneste, P.; Moreau, C. Kinetics of furfuryl alcohol hydroxymethylation with aqueous formaldehyde over a highly dealuminated H-mordenite. J. Mol. Catal. A Chem. 1998, 133, 283-288. [CrossRef]

44. Lecomte, J.; Finiels, A.; Geneste, P.; Moreau, C. Selective hydroxymethylation of furfuryl alcohol with aqueous formaldehyde in the presence of dealuminated mordenites. Appl. Catal. A Gen. 1998, 168, $235-241$. [CrossRef]

45. Lecomte, J.; Finiels, A.; Moreau, C. A new selective route to 5-hydroxymethylfurfural from furfural and furfural derivatives over microporous solid acidic catalysts. Ind. Crops Prod. 1999, 19, 235-241. [CrossRef] 
46. Lecomte, J.; Finiels, A.; Geneste, P.; Moreau, C. Attempt to quantify the hydrophobic character of highly dealuminated H-mordenites in hydroxymethylation of furfuryl alcohol with aqueous formaldehyde. J. Mol. Catal. A Chem. 1999, 140,157-163. [CrossRef]

47. Everett, D.H.; Powl, J.C. Adsorption in slit-like and cylindrical micropores in the henry's law region. A model for the microporosity of carbons. J. Chem. Soc. Faraday Trans. 1976, 72, 619-636. [CrossRef]

48. Ono, Y.; Hattori, H. Solid Base Catalysis. In Springer Series in Chemical Physics 101; Springer: Berlin/Heidelberg, Germany; Tokyo Institute of Technolgy Press: Tokyo, Japan, 2011.

49. Imelik, B.; Naccache, C.; Taarit, Y.B.; Vedrine, J.C.; Coudurier, G.; Praliaud, H. Catalysis by Zeolites. In Studies in Surface Science and Catalysus 5; Elsevier: Amsterdam, The Netherlands, 1980.

50. He, Y.; Hoff, T.C.; Emaadi, L.; Wu, Y.; Bouraima, J.; Liu, D. Catalytic consequences of micropore topology, mesoporosity, and acidity on the hydrolysis of sucrose over zeolite catalysts. Catal. Sci. Technol. 2014, 4, 3064-3073. [CrossRef]

51. Li, H.; Yang, S.; Riisager, A.; Pandey, A.; Sangwan, R.S.; Saravanamurugan, S.; Luque, R. Zeolite and zeotype-catalysed transformations of biofuranic compounds. Green Chem. 2016, 18, 5701-5735. [CrossRef]

52. Otomo, R.; Yokoi, T.; Kondo, J.N.; Tatsumi, T. Dealuminated Beta zeolite as effective bifunctional catalyst for direct transformation of glucose to 5-hydroxymethylfurfural. Appl. Catal. A Gen. 2014, 470, 318-326. [CrossRef]

53. Otomo, R.; Tatusmi, T.; Yokoi, T. Beta zeolite: A universally applicable catalyst for the conversion of various type of sacchrides into furfural. Catal. Sci. Technol. 2015, 5, 4001-4007. [CrossRef]

54. Gebresillase, M.N.; Shavi, R.; Seo, J.G. A comprehensive investigation of the condensation of furanic platform molecules to $\mathrm{C}_{14}-\mathrm{C}_{15}$ fuel precursors over sulfonic acid functionalized silica supports. Green Chem. 2018, 20, 5133-5146. [CrossRef]

55. Arias, K.S.; Al-Resayes, S.I.; Climent, M.J.; Corma, A.; Iborra, S. From Biomass to Chemicals: Synthesis of precusors of Biodegradable Surfactants from 5-Hydroxymethylfurfural. ChemSusChem 2013, 6, 123-131. [CrossRef]

56. Galkin, K.I.; Krivodaeva, E.A.; Romashov, L.V.; Zalesskiy, S.S.; Kachala, V.V.; Burykina, J.V.; Ananikov, V.P. Critical Infulence of 5-Hydroxymethylfurfural Aging and Decomposition on the Utility of Biomass Conversion in Organic Synthesis. Angew. Chem. Int. Ed. 2016, 55, 8338-8342. [CrossRef]

57. da Silva, C.X.A.; Goncalves, V.L.C.; Mota, C.J.A. Water-tolerant zeolite catalyst for the acetalisation of glycerol. Green Chem. 2009, 11, 38-41. [CrossRef]

58. Zapata, P.A.; Faria, J.; Ruiz, M.P.; Jentoft, R.E.; Resasco, D.E. Hydrophobic Zeolites for Biofuel Upgrading Reactions at the Liquid-Liquid Interface in Water/Oil Emulsions. J. Am. Chem. Soc. 2012, 134, 8570-8578. [CrossRef] [PubMed]

59. Kuwahara, Y.; Aoyama, J.; Miyakubo, K.; Eguchi, T.; Kamegawa, T.; Mori, K.; Yamashita, H. $\mathrm{TiO}_{2}$ photocatalyst for degradation of organic compounds in water and air supported on highly hydrophobic FAU zeolite: Structural, sorptive, and photocatalytic studies. J. Catal. 2012, 285, 223-234. [CrossRef]

60. Chen, N.Y. Hydrophobic Properties of Zeolite. J. Phys. Chem. 1976, 80, 60-64. [CrossRef]

(C) 2019 by the authors. Licensee MDPI, Basel, Switzerland. This article is an open access article distributed under the terms and conditions of the Creative Commons Attribution (CC BY) license (http:// creativecommons.org/licenses/by/4.0/). 